\title{
Recent Advances in Polarography in Japan
}

\author{
Nobuyuki TANAKA, Eiki ITA BASHI and Tasuku ITO
}

Department of Chemistry, Faculty of Science, Tohoku University, Sendai

Received September 5, 1964

\section{Introduction}

In the end of the 1940's and the beginning of the 1950's two milestones were placed in the field of polarography. One was a kinetic treatment of polarographic current-potential curves, which was first introduced by Eyring and his co-workers in the United States ${ }^{1)}$ as 'well as by Tanaka and Tamamushi in Japan 2),3). The other was a rigorous treatment of a mass transfer problem, which was developed first by Kambara and Tachi in Japan 4) as well as by several groups of investigators in the world ${ }^{5)-7)}$. The introduction of these two treatments provided the basis of modern polarography which has been developed in the last ten years.

This review is concerned chiefly with the progress in polarography which has been made in Japan and by Japanese polarographists since 1960. The leading aim is to describe the essential feature of the progress but not to prepare the complete compilation of polarographic literature in this period.

The most of papers concerning polarography and its applications are published in many home journals including Bulletin of the Chemical Society of Japan, Nippon Kagaku Zasshi (Journal of the Chemical Society of Japan, Pure Chemistry Section), Denki-Kagaku (Journal of the Electrochemi- cal Society), Bunseki Kagaku (Japan Analyst) and Review of Polarography. Some are published overseas. The Review of Polarography is published bimonthly from the Polarographic Society of Japan and contains original papers written mostly in English and review papers written in Japanese. A number of polarographic papers are presented at annual meetings of the Chemical Society and other societies, and also at the Annual Symposium of Polarography which is held under the auspices of several societies including the Polarographic Society of Japan.

Several books and many reviews mostly written in Japanese language are published since 1960. Some are written in English and published overseas ${ }^{8)-12)}$. The Japan Society. for Analytical Chemistry and the Electrochemical Society of Japan publish "Advances in Analytical Chemistry" every year as a special publication of Bunseki Kagaku and "Advances in Electrochemistry" every other year as a special publication of Denki-Kagaku, respectively. In these publications, polarography, polarographic theory, instrumentation, inorganic polarography and organic polarography are frequently reviewed. The Polarographic Society of Japan has edited and published "Polarography Data Card" (in English) since 1962.

A compilation of kinetic parameters of electrode reactions was made by Tanaka 
and Tamamushi and presented at the Montreal meeting of the Commission on Electrochemical Data, Analytical Chemistry Section, IUPAC, 1961. It was transferred to the Commission on Electrochemistry, Physical Chemistry Section, and recommended by the Commission for publication 13).

In addition to several kinds of the conventional direct current and alternating current polarographs and other related instruments, a Barker-type square-wave polarograph, "High Sensitive Polarograph," has been produced since 1960. A new type of polarograph, "High Frequency Polarograph", which was devised on the basis of the faradaic rectification, has been recently produced.

\section{Classical Polarography}

Progress has been made mainly in the application of the polarographic method in various fields of chemistry.

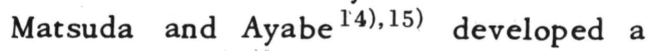
general method for analysis of the polarographic current-potential curves of the system in which a series of different species of metal complexes present in the solution are in equilibrium and all of them may participate in the electron-transfer processes. They applied the method to the study of the electrode processes of zinc (II) in solutions containing various complexforming substances. The theoretical treatment of the electrode reactions of metal complexes was reviewed ${ }^{16)}$.

The method for the determination of the heat of activation of an electron transfer process was discussed by Tamamushi 17). He proposed that the potential of the working electrode should be referred to the potential of "zero-charge of metal" or "null-point of metal" if the true heat of activation is to be determined.

The kinetic parameters of electrode reactions of zinc(II) in various media were determined with the theoretical equation for the quasi-reversible current-potential curve derived by Matsuda and Ayabe, and a. possible mechanism of the electrode reaction of zinc(II) in the solutions containing halide ions was discussed, when the acceleration effect of adsorbed halide ions on the reduction of zinc(II) ions at the dropping mercury electrode was pointed out 18), 19)

The polarographic behavior of tripositive lanthanide ions in various electrolyte solutions ${ }^{20)-24)}$ and that of iron(III), in the solutions containing various complexforming reagents ${ }^{25), 26)}$ were investigated.

In addition to the substitution-labile complexes, the electrode reactions of the substitution-inert complexes at the dropping mercury electrode have been investigated. Maki 27),28) published reviews on the polarography of the substitution-inert complexes. The formation of the cobalt complexes of lower valencies was demonstrated by the polarographic reduction of the substitution-inert cobalt(III) complexes. The polarographic behaviors of those complexes were also investigated ${ }^{29)-31)}$.

The electrode reactions of substitutioninert chromium(III) complexes have been studied by Tanaka and his coworkers 32)36) by polarographic and other electrochemical techniques. These investigations revealed that the polarographic reduction waves of chromium(III) complexes are greatly affected by the dissociation (or substitution) reaction of chromium(II) complexes which are produced through the electron-transfer reaction. Tanaka and Satô ${ }^{32)}$ emphasized the role of the hydrogen ions in the reduction of the chromium(III) complexes which contain basic ligands. It was pointed out that the reduction potentials of the substitution-inert complexes are dependent on the ionic charge of the complex ions ${ }^{34)}$ 
Theoretical equations were derived for the polarographic current of the consecutive electrode processes in which the product of the first electrochemical reaction is changed to the other electroactive species by a chemical reaction. The equations were applied to the analysis of the polarographic behavior of $p$-nitrosophenol ${ }^{37)}$. The consecutive electrode reactions in which a chemical reaction following the first electrochemical process is of a secondorder reaction was also dealt with from the theoretical stand point, and the theoretical expression for the rate constant of the chemical reaction was derived. The results were applied to the polarographic reduction of hexammine- and hexaquochromium(III) complexes in the presence of ethylenediaminetetraacetate, and the rate constant for the reaction of hexaquochromium(II) and ethylenediaminetetraacetate ions was estimated ${ }^{38), 39 \text { ) }}$

The polarographic investigation of the chromium(III) Eriochrome Violet B complexes indicates that the ligand Eriochrome Violet $B$ is first reduced, and then the reduction of the central metal ion chromium (III) takes place at more negative potentials. The reduction potential of the coordinated Eriochrome Violet B was found considerably more negative than that of the free dye 40). Similar consecutive reductions where both ligands and a central metal ion are reduced have been observed with organometallic compounds 41),42)

Investigations on the mechanism of the Brdička catalytic wave have been carried out by Shinagawa with his coworkers ${ }^{43)-}$ 49), who also published a review on the phenomena ${ }^{50)}$.

The electrode reactions of Vitamin $B_{1}$ (thiamine) ${ }^{51)-53)}$, Vitamin $C^{54), 55)}$ and their related compounds have been investigated by several authors. Polarographic reduction waves were observed in organic solvents with Vitamin $A, \beta$-carotene and Vitamin $\mathrm{D}_{2}{ }^{56)}$, which gave no reduction wave in aqueous solutions ${ }^{57)}$. The limiting current of the reduction wave of trimethylpyruvic acid was found to be kinetic-controlled under certain conditions and the mechanism of the electrode reaction of the acid was discussed ${ }^{58)}$.

The polarographic "maximum" and "minimum" have been discussed. Takamura ${ }^{59)}$ reported on the exaltation effect of anthracene on the polarographic maximum of methyl-p-benzoquinone, and concluded that the effect is due to the preferential adsorption of anthracene on the surface of the mercury electrode. The "minimum" was observed on the current-potential curves for the reductions of indium(III)thiocyanate ${ }^{60)-62)}$ nickel(II)-thiocyanate 61) and manganese(III)-tartrate ${ }^{63)}$ complexes. The uccurrence of the minimum was interpreted from the standpoint of the electrode kinetics in the case of the indium (III)-thiocyanate complex; it was assumed that the adsorption of thiocyanate ions accelerates the electron transfer of the complex and that consequently simultaneous electrochemical reactions take place at the naked and the covered surface of the electrode ${ }^{60)}$.

A review is given of adsorption of surface-active substances at the mercurysolution interface, especially, with regard to the structure of adsorbed layers ${ }^{64)}$. The adsorption behaviors of various surfaceactive substances at the mercury-solution interface ${ }^{65), 66)}$ and those of alkali halides and sodium dodecyl sulfate in mixed solvents containing dioxane ${ }^{67)-69)}$ have been investigated.

The effects of cyclohexanone and some of its C-alkyl derivatives on the polarographic currents of certain inorganic substances have been studied. The tensammetric measurements revealed the formation of a film of cyclohexanone on the surface of the dropping mercury electrode ${ }^{70}$. 
The cathodic and anodic current-voltage curves of lead, copper, cadmium and zinc in potassium nitrate solutions and those of trioxalatoferrate and hexacyanochromate were found to be generally affected by the addition of polyoxyethylene lauryl ether (LEO), except the anodic wave of copper. The effect of LEO on the current-voltage curve of trioxalatoferrate was much larger than on those of the hexacyanochromate i1). The dual effect-the accelaration and the retardation - of the electron-transfer process of the manganese(III)-tartrate complex was demonstrated ${ }^{72)}$.

\section{Alternating Current Polarography and Oscillographic Polarography}

\section{Alternating Current Polarography}

There have been a considerable number of studies of the theory, instrumentations and applications in the field of alternating current(a.c.) polarography. A special publication concerning reviews on a.c. polarography has been edited by Fujinaga and Maruyama ${ }^{73)}$. A.c. polarographs of Japanese manufacture have been developed in two ways; one with an a.c. bridge and the other with a commutator. Most of the studies have been carried out by means of the polarograph equipped with an a.c. bridge. The modification of the Breyer's a.c. polarograph has been reported; an auxiliary resistance and capacitance circuit is attached, which compensates for the resistance and capacitance of the electrolysis cell and counter-balances the residual current ${ }^{74)}$.

The relation between the a.c. peak height and the rate constant of electrode reactions was pointed out, and the term "degree of reversibility" was defined as a function of the ratio of the limiting current in a d.c. polarogram to the peak current in an a.c. polarogram ${ }^{75)}$. The quantitative expression for the relationship between the a.c. peak current and the rate constant of the electrode reactions was derived on the basis of the theoretical treatment reported previously by Kambara and that by Matsuda. This was applied to the determination of the rate constants of the electrode reactions of some metal ions in various supporting electrolyte solutions ${ }^{76)}$.

The "peak current constant," $i_{\mathrm{p}} / \mathrm{Cm}^{2 / 3} t_{d}{ }^{2 / 3}$, is introduced, where $i_{p}, C, m$ and $t_{d}$ represent the peak current, the concentration of the electroactive substance, the rate of flow of the dropping mercury electrode and the drop time, respectively ${ }^{77)}$. The peak current constant in a.c. polarography corresponds to the diffusion current constant in d.c. polarography. The a.c. polarographic behaviors of various metal ions are investigated in various supporting electrolyte solutions ${ }^{78-80)}$ and compared with the d.c. polarographic behaviors of these metal ions 78),79). Organic compounds have also been investigated by the a.c. polarographic method 49$), 53), 80), 81$ )

A theoretical treatment for the tensammetric waves was developed by Senda and Tachi ${ }^{82)}$, on the basis of the kinetic theory of adsorption at the mercury-solution interface. Dodecylbenzene sulfonate was found to give a distinct tensammetric wave in an aqueous solution of sodium sulfate and to affect remarkably the tensammetric peak of cyclohexanol ${ }^{83}$.

\section{Oscillographic Polarography}

Several reviews have been published on the principle, theory, instrumentation and applications in oscillographic polarography 84).

A few investigations on the mechanism of electrode reactions carried out by the oscillographic polarography and some analytical applications have been reported. 
The method was applied to the study of the catalytic double-wave of cystine in ammonia-ammonium chloride buffer solutions containing divalent cobalt ions, gelatin and methyl cellulose ${ }^{85)}$. In the oscillograph-polarographic study of lanthanum, europium and ytterbium carried out in various supporting electrolyte solutions, Misumi and Ide ${ }^{86)}$ clarified the effect of dissolved oxygen and hydrogen peroxide on the depolarization of lanthanum ions in a non-buffered potassium chloride solution. They also confirmed the formation of lanthanum hydride or lanthanum halogen hydride as an electrolysis product. The oscillograph-polarographic method was used as an auxiliary technique for the study of inorganic metal complexes ${ }^{87)}$.

"Oscillographic square-wave polarograph," which is, in principle, a combination of the Barker's square-wave polarograph and the modified Randles-Sevičik's single-sweep oscillographic polarograph, was devised by Saito and Okamoto ${ }^{88)}$. The theory for the oscillographic squarewave polarography was developed and the behaviors of inorganic and organic substances were investigated ${ }^{89)-91)}$.

\section{Chronopotentiometry and Chronoamperometry}

\section{Chronopotentiometry}

The theory and practice of chronopotentiometry is reviewed by Senda and Nagai ${ }^{92)}$.

A graphical method was proposed to determine the $E_{\tau / 4}$ potential and the transition time in the case when two or more electroactive substances are present in the solution 93). It was applied to the chronopotentiograms for the reduction of thallium(I), lead(II) and cadmium(II) in a $0.1 M$ potassium nitrate solution with the satisf actory results.

Chronopotentiometric studies of several metal ions have been carried out by Ishibashi and his coworkers ${ }^{94), 95)}$ in various supporting electrolyte solutions. These researchers discussed on the quarter-wave potentials and the transition time constants of the cathodic chronopotentiograms obtained in various electrolyte solutions and also on the effect of surface-active substances on those chronopotentiograms.

The potential-time curves obtained at the slowly dropping mercury electrode was dealt with from the theoretical and the experimental standpoint 96),97). It was realized that the use of the chronopotentiometric method with such an electrode seemed promising in the field of quantitative microanalysis, especially for the determination of a micro quantity of electroreducible substance in the presence of large quantities of substances which are reducible at less negative potentials.

The derivative chronopotentiometry has been developed; the slowly dropping mercury electrode was used and a differential circuit was attached to the recorder ${ }^{98)}$. It is reported that the derivative chronopotentiometry has an advantage in the determination of a micromolar quantity because of its greater sensitivity ${ }^{98}$. Alternating current chronopotentiometry has also been developed from the theoretical and the practical standpoint; the theoretical equation for the electrode reaction of a reversible type has been derived ${ }^{99)}$.

The chronopotentiometric studies on the reduction of mercury(II) cyanide and cyanomercurate(II) complexes and the oxidation of cyanide ions and hydrogen cyanide has been reported ${ }^{100)}$. The rate of the dissociation of nitrilotriacetatocadmate(II) complexes was determined from the change in the chronopotentiometric transition time with the current density. The result was compared with the rate estimated from the polarographic kinetic 
current with a satisfactory agreement ${ }^{101)}$. This is one of a few investigations in which the rate of the same reaction is determined by both polarographic and chronopotentiometric methods. Surface-active substances affect the transition time as well as the shape of chronopotentiograms. The effect of the aging of a hanging mercury drop electrode on the chronopotentiograms of thallium(I), lead(II) and cadmium(II) was investigated, and it was found, especially in the case of cadmium, that even the aging for the short period gave a significant change both in the potential and the transition time ${ }^{100}$ ). The chronopotentiometric study of the adsorption wave of flavinmononucleotide was carried out, and the adsorption mechanism was discussed ${ }^{102)}$.

\section{Chronoamperometry}

This technique is often called "potentiostatic" and an electronic potentiostat is required for the measurement of the current-time relation. The theory, the instrumentation and the application have been reviewed by Oka and Matsuda ${ }^{103}$.

The method has been applied to the elucidation of the Brdička catalytic reactions of cysteine and cystine. The results were discussed with the aid of the threedimentional model which consisted of three rectangular coordinates, $i, E$ and $t^{104)}$.

Kinetic parameters of the electrode reactions of zinc(II), copper(II) and cadmium(II) were determined by the potentiostatic method ${ }^{105)}$. The values obtained are in fair agreement with those reported in the literature.

The application of the chronoamperometry to the trace analysis was discussed from the theoretical standpoint, and the experimental results obtained with zinc(II), manganese(II), cadmium(II) and thallium(I) ions were compared with those obtained by the conventional polarographic method ${ }^{106)}$

\section{Other Modifications in Methodology}

\section{Current Scanning Polarography}

A new polarographic technique in which the current applied to the electrolysis cell is increased continuously and the potential of the dropping mercury electrode is recorded against a suitable reference electrode has been introduced 107). This is named "current scanning polarography" or "constant-current polarography." The theory and practice concerning this method is reviewed by Fujinaga $\left.{ }^{8}\right), 108$ ).

\section{Kalousek Polarography}

The polarographic measurement with the Kalousek circuit has been applied to the study of electrode processes at the dropping mercury electrode ${ }^{109)}$. Kalousek Polarograms can be conveniently recorded by means of a pen-recording polarograph ${ }^{110}$. The mechanical commutator in the Kalousek circuit was replaced by a simple relay circuit, which has advantages over the mechanical commutator because of its convenience, the constancy and reliability of its switching action and its wide range of exchange frequencies provided ${ }^{10), 110)}$.

The Kalousek method seems to be one of the promising techniques for the qualitative investigation of the reversibility as well as the mechanism of the electrode reactions at the dropping mercury electrode.

\section{Faradaic Impedance Measurement}

Reviews on the measurement and the analysis of faradaic impedance are written by Tamamushi 111) and Hashino ${ }^{112)}$.

The kinetic parameters for the reduction of cadmium(II) and zinc(II) in $1 M$ potassium chloride solutions and those for the reduction of thallium(I) in various electrolyte solutions were determined by the measure- 
ment of faradaic impedance at the dropping mercury electrode ${ }^{113), 1 i 4)}$. The adsorption of thallium(I) at the mercury-solution interface was pointed out ${ }^{114)}$.

\section{Other Types of Electrodes}

Besides the conventional dropping mercury electrode, various types of mercury electrodes as well as electrodes of other metals have been devised, proposed, investigated and discussed.

\section{Mercury Electrodes}

A vibrated dropping mercury electrode (VDME), of which the dropping electrode is vibrated by applying the alternating current field, has been developed. It was used for the determination of the potential of electrocapillary maximum, and proved to be very useful because of reproducibility, accuracy and rapidity in the measurement ${ }^{115}$. The quantitative expression for the limiting current at the VDME has been derived ${ }^{116}$. The remarkable effect of surface-active substances on the limiting current and the effect of the frequency of vibration on the summit potential of the polarographic maximum and on the potential of the electrocapillary maximum were reported ${ }^{117)}$.

The rapidly dropping mercury electrode (RADME) was applied to the measurement in direct current and alternating current polarography 118),119). The characteristics of the RADME in d.c. and a.c. polarography was investigated. The current-time characteristics indicated that the limiting current in d.c. polarography was controlled both by diffusion and convection in the potential region where the mercury surface was in motion. At the RADME, so-called "maxima of the second kind" were observed ${ }^{120)}$. An investigation on the effect of surface-active substances on the polarograms obtained with the RADME showed that for the sup- pression of the maxima a larger amount of surface-active substance was required in the case of the RADME than the DME ${ }^{119}$. The RADME was also used for an indicator electrode in the alternating current polarographic titration of metal ions ${ }^{121}$.

A slowly dropping mercury electrode (SDME) was applied to the chronopotentiometric measurement, and proved to be very suitable ${ }^{96)}$.

Because of the relative simplicity. both theoretical and experimental, a hanging mercury drop electrode (HMDE) has been used in the study of the electrode reactions, especially in chronopotentiometric and chronoamperometric studies. As has been mentioned above, the electrode was used for the chronopotentiometric studies of simple and complex ions and of the dissociation reactions of hydrogen cyanide and nitrilotriacetatocadmate(II) complexe $\mathrm{s}^{100}$, 101). An attempt was made to develop the alternating current polarography with the hanging mercury drop electrode. The application of the method to several metal ions indicated that the HMDE has a greater sensitivity than the conventional DME ${ }^{122}$.

The application of a stationary mercury pool electrode to the polarographic measurement in supporting electrolyte solutions of high viscosity was studied. A good reproducibility was attained and polarograms similar to those obtained with the conventional DME were observed ${ }^{123}$.

The theory, instrumentations and practical applications of the rotated dropping mercury electrode and the rapidly dropping mercury electrode have been reviewed by

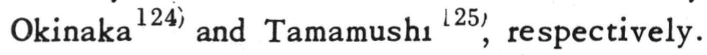

\section{Solid Electrodes}

Ar extensive study has been made concerning the preparations, the characteristics and the applications of various kinds of convection electrodes of platinum 
wire ${ }^{126)}$ mercury-coated platinum wire ${ }^{127)}$, electrodeposited mercury drop on platinum wire ${ }^{128)}$ and pushed-out mercury drop on platinum wire ${ }^{129)}$. The electrolysis cell was equipped with a rotating disk which caused the convection of the solution at the electrode. A "pushed-out mercury drop convection electrode" was also devised. The investigation of the characteristics of the electrode revealed that the limiting current was controlled by both diffusion and convection ${ }^{129)}$. The electrode seems to be advantageous in the determination of micromolar solutions because of its extremely high sensitivity.

A dipping molybdenum microelectrode has been used in the voltammetric studies of various metal ions in aqueous solutions ${ }^{130}$.

The characteristics of a platinum electrode and the electrode processes at the electrode have been investigated ${ }^{131), 132)}$. The mechanisms of the ionization of molecular hydrogen, the reduction of oxygen, the effect of various cations and anions on the reduction of oxygen molecules and the state of electrode surface before and after the polarization were discussed ${ }^{131}$. In the voltammetric and chronopotentiometric studies of hydrogen ions at the platinum electrode in sulfuric acid, the electrolytic formation of an oxide layer at the electrode surface was demonstrated and its mechanism is presented ${ }^{132)}$.

\section{Polarography in Non-aqueous Solvents and in Fused Salts}

In recent years, an increasing attention has been devoted to polarography in nonaqueous solvents, mixed solvents and in fused salts. Reviews are given by Takahashi ${ }^{133)}$ and Ikeda ${ }^{134)}$ on the experimental techniques and the polarographic behaviors of inorganic and organic substances in nonaqueous solvents.
The polarographic reduction of some inorganic depolarizers were investigated in dimethylacetamide ${ }^{135)}$ and in wateracetonitrile mixture ${ }^{136)}$. In the latter study, the half-wave potential of thallium(I) was taken as standard in both the aqueous acetonitrile and the aqueous solution.

Polarography in fused salts is reviewed by several authors 137-140). The use of various solid microelectrodes in polarography in fused lithium chloride-potassium chloride eutectics has been discussed ${ }^{141}$. High temperature polarography of various metal oxides dissolved in molten bath of $\left.\mathrm{Na}_{3} \mathrm{AlF}_{6}-\mathrm{CaF}_{2} 142-145\right)$ and $\mathrm{Na}_{2} \mathrm{~B}_{4} \mathrm{O}_{7}{ }^{146)}$ at platinum microelectrode has been reported.

Investigations were made on the reduction of several metal ions in the fused mixture of lithium chloride, potassium chloride and aluminum chloride with the dropping mercury electrode and also in the eutectic mixture of lithium chloride and potassium chloride with the dipping molybdenum microelectrode ${ }^{147)}$. The polarographic determination of lead sulfate and cadmium oxide was carried out in molten ammonium hypophosphite of $120^{\circ} \mathrm{C}$ with the dropping mercury electrode ${ }^{148)}$.

\section{Applications}

Polarography and the related techniques have been used in many fields of chemistry as well as in chemical industry. A number of papers and reviews dealing with the applications of these techniques have been published. Progress in theory and instrument has made the application considerably wider. The increase in sensitivity and accuracy has made the polarographic method more applicable not only in the field of analytical chemistry but also in the fields of physical, inorganic, organic chemistry. In this review, certain examples of the applications of the polarographic and 
the related techniques are presented.

In addition to the conventional direct current polarograph, the alternating current polarograph and the square-wave polarograph have been used in chemical analysis, especially, in the determination of minute quantities of substances. The polarographic titration by means of an a.c. polarograph and a square-wave polarograph has been developed and applied to the determination of various substances.

The combinations of polarography and other techniques have also been investigated. Chromato-polarography, which is one of the combinations, has been studied by Shinagawa and his coworkers 149),150). Extraction polarography, which is also one of them and the combination of solvent extraction and polarography, is considered to be a convenient tool for the determination of minute constituents of a sample. The application of the method to chemical analysis is reviewed by Nakagawa ${ }^{151)}$. Further device and improvement ${ }^{152)}$ made the application of extraction polarography simpler, more rapid and more accurate.

Radiometric polarography has been utilized in various kinds of investigations ${ }^{153}$ ). By measuring the radioactivity of each drop of mercury of the dropping mercury electrode as a function of potential, a current-potential curve can be obtained. This technique does not require the measurement of current and, consequently, can be applied to the solution of extremely low concentration. The application of polarography to radiochemistry has been reviewed 154),155).

The technique of electrochemical masking was introduced by Fujinaga into polarographic analysis 156),157). One of the applications of this technique is that the trace of thallium is successfully determined in the presence of large quantities of copper by careful selection of supporting electrolyte and surface-active substance; copper is reduced at less negative potentials under the usual conditions.

The use of a substitution-inert metal complex such as hexamminechromium (III) as a metal indicator in the a.c. polarographic titration has been reported ${ }^{158)}$.

The application of chronopotentiometric method in chemical analysis has been established, as was mentioned before.

Polarography and the related techniques have been widely used in physical and inorganic chemistry. $A$ number of investigations have been carried out on the determination of the formation constants of metal complexes. A new polarographic method which is suitable for the determination of the formation constants of weak complexes has been devised. The method is based on the polarographic measurement of the sum of the equilibrium concentrations of hydrated metal ions and complexed ions of the weak complex in the presence of an appropriate auxiliary complex-forming substance. The measurement of the limiting current but not the half-wave potential is a fundamental advantage of this method. The formation constants of acetato, sulfato and sulfatoacetato complexes of various divalent metals have been determined ${ }^{159-162)}$. The equilibrium constants of various substitution reaction involving ethylenediaminetetraacetato complexes are reported by the same authors.

The method based on the shift of the half-wave potential has also been applied to the determination of the formation constants of metal complexes. Nitrilotriacetato, diethylenetriaminepentaacetato and carbonato complexes of rare earth metals 23),24),26) nitrilotriacetato complexes of copper(II) ${ }^{163)}, \quad z_{\text {inc(II) }}{ }^{164)}$ and thallium (I) ${ }^{165)}$ have been dealt with.

A series of substitution reactions be- 
tween metal ions and ethylenediamminetetraacetato complexes in aqueous solutions have been investigated by following the change in the limiting diffusion current of metal ions with time ${ }^{166-172)}$. The method is considered to have an advantage in the accurate analysis of kinetics of this kind of reactions.

The theoretical studies on the relationship between the polarographic reduction potential and the electronic structure of the depolarizer has been considered as one of the most interesting subject. A few Japanese polarographists have dealt with this subject and reported that the polarographic reduction potentials of some aromatic aldehydes and nitro compounds ${ }^{173)}$, vinyl compounds ${ }^{174)}$, haloalkane and the conjugated halides ${ }^{175)}$ are connected with the energies of their lowest unoccupied levels. Their statement, although important, is considered still open to question.

The measurement of electron spin resonance has been carried out with the electrolysis product at the mercury electrode. The formation of free radicals by electrolysis could be observed. On the other hand, the electrolysis is recommended for the generation of free radicals, because the conventional chemical technique may produce complications by introducing interfering species into the solution ${ }^{176)}$. It is suggested that the polarographic half-wave potentials of nitrobenzene derivatives are correlated to the nitrogen coupling constants of the anion radicals of these compounds ${ }^{177}$ ). The electrode reactions have been discussed with the aid of the results obtained by the measurement of electron paramagnetic resonance. The possibility of the application of the ESR measurement to inorganic polarography was recently suggested.

Many applications of polarography in other fields of chemistry and the chemical industry as well as pharmacy and medical research have been reported. Several reviews written in Japanese language 178),179) have been published except one which is written in English by Tachi and Senda 11) on the application of polarography in the chemical industry.

\section{Literature:}

1) H. Eyring, L. Marker and T.C. Kwoh, J. Phys. Colloid Chem. 53, 1453 (1949).

2) N. Tanaka and R. Tamamushi, Bull. Chem. Soc. Japan 22, 187(1949); Proceedings of the First International Polarographic Congress, Prague, Part I, 1951 , p. 486.

3) R. Tamamushi and N. Tanaka, Bull. Chem. Soc. Japan 22, 227 (1949).

4) T. Kambara and I. Tachi, ibid. 25, 135 (1952).

5) P. Delahay, J。 Am. Chem. Soc. 73, 4944 (1951).

6) M. Smutek, Chem. Listy 45, 241 (1951); Collection Czech. Chem. Commun. 18, 171 (1953).

7) M. G. Evans and N. S. Hugh, J.Chim. Phys. 49, C159 (1952).

8) T. Fujinaga, "Progress in Polarography," ed. by P. Zuman and I. M. Kolthoff, Vol. I, Interscience, New York (1962), p. 201.

9) I. M. Kolthoff and Y. Okinaka, ibid. Vol. II (1962), p. 357.

10) N. Tanaka, ibid. p. 523.

11) I. Tachi and M. Senda, ibid. p. 711.

12) N. Tanaka, "Treatise on Analytical Chemistry" ed. by I. M. Kolthoff and P. J. Elving, p. 2417. (1963) Interscience, New York.

13) N. Tanaka and R. Tamamushi, Electrochim. Acta 9, 963 (1964).

14) H. Matsuda and Y. Ayabe, Z. Elektrochem. 63, 1164 (1959); 66, 469 (1962). 
15) H. Matsuda; Y. Ayabe and K. Adachi, Ber. Bunsenges. Physik. Chem. 67, 593 (1963).

16) Y. Ayabe, Kagaku Kogyo Shiryo 31, 228 (1963).

17) R. Tamamushi, Rev. Polarog. (Kyoto) 10, 1 (1962).

18) R. Tamamushi, K. Ishibashi and N. Tanaka, Z. Phys. Chem. N. F. 35, 209 (1962).

19) R. Tamamushi and N. Tanaka, ibid. 39, 117 (1963).

20) J. Hashimoto, Hitotsubashi Daigaku Jinbunkagaku-Shizenkagaku Kenkyu Nenpo 4, 225 (1962).

21) A. Iwase, Nippon Kagaku Zasshi 80, 1133 (1959); 81, 95, 739, 1266, 1486, 1706 (1960).

22) S. Misumi and Y. Ide, Bull. Chem. Soc. Japan 32, 1159 (1959); 33, 836 (1960).

23) S. Misumi and Y. Masuda, Anal. Chim. Acta 28, 188 (1963).

24) S. Misumi and A. Iwase, Rev. Polarog. (Kyoto), 11, 146 (1963).

25) A. Yamada, Nippon Kagaku Zasshi 8.3, 684 (1962); 84, 224, 231, 488, 709, 719 (1963).

26) S. Misumi and Y. Masuda, J. Electroanal. Chem. 6, 434 (1963).

27) N. Maki, Kagaku 14, 632 (1959); 16, 202 (1961).

28) N. Maki, Rev. Polarog. (Kyoto) 9, 203 (1961).

29) N. Maki, Nature 185, 682 (1960); 188, 227 (1960).

30) N. Maki, T. Hirano and S. Musha, Bull. Chem. Soc. Japan 36, 756 (1963).

31) N. Maki and H. Itatani, ibid. 36, 757 (1963).

32). N. Tanaka and G. Satô, Nature 197, 176 (1963).

33) N. Tanaka, K. Ebata and G. Satô, Bull. Chem. Soc. Japan 36, 912 (1963).

34) N. Tanaka, E. Itabashi and E. Kyuno, ibid. 36, 917 (1963).
35) N. Tanaka, Y. Sato, R. Tamamushi and G. Sato, ibid. 36, 1059 (1963).

36) N. Tanaka, E. Itabashi, R. Tamamushi and G. Sato, ibid. 37, 226 (1964).

37) I. Tachi and M. Senda, "Advances in Polarography" ed. by I. S. Longmuir, Vol. 2, p. 454., I (1960), Pergamon, London

38) N. Tanaka and K. Ebata, J. Electroanal. Chem. 8, 120 (1964)

39) K. Ebata, Sci. Repts. Tohoku Univ. First Ser. 47, 191 (1964)

40) G. H. Aylward and N. Tanaka, Rev. Polarog. (Kyoto) 11, 204 (1963).

41) H. Imai and H. Saito, Nippon Kagaku Zasshi 84, 317 (1963).

42) K. Yasukouchi and N. Urabe, Kogyo Kagaku Zasshi 64, 1048 (1961); 65, 51, 892 (1962); Nippon Kagaku Zasshi 84, 215 (1963).

43) M. Shinagawa, H. Nezu, H. Sunahara, F. Nakashima, H. Okashita and T. Yamada, "Advances in Polarography", ed. by I.S. Longmuir, Vol. 3, p. 1142. (1960), Pergamon, London.

44) M. Shinagawa and H. Nezu, Bull. Chem. Soc. Japan 33, 272 (1960).

45) M. Shinagawa, H. Imai and H. Nezu, ibid. 34, 446 (1960).

46) M. Shinagawa, H. Nezu and T. Yamada, Rev. Polarog. (Kyoto) 10, 126 (1962).

47) H. Nezu, ibid. 10, 154 (1962).

48) H. Sunahara, ibid. 9, 158 (1961).

49) H. Sunahara, ibid. 9, 165, 222, 233 (1961).

50) M. Shinagawa, ibid. 9, 135 (1961).

51) Y. Asahi, Yakugaku Zasshi 80, 1093, 1097, 1226 (1960).

52) I. Tachi, M. Senda, S. Shibata and T. Maruyama, "Advances in Polarography", ed. by I. S. Longmuir, Vol. 3, p.1099. (1960), Pergamon, London

53) K. Okamoto, Bull. Chem. Soc. Japan 34, 920, 1063 (1961); 36, 366, 371 (1963). 
54) S. Ono, M. Takagi and T. Wasa, ibid. 31, 356, 364 (1958).

55) T. Wasa, M. Takagi and S. Ono, ibid. 34, 518 (1961).

56) R. Takahashi, Rev. Polarog. (Kyoto) 9, 247 (1961).

57) Y. Asahi, ibid. 8, 1 (1960).

58) M. Takagi, Bull. Chem. Soc. Japan 34, 905 (1961).

59) K. Takamura, ibid. 36, 1053 (1963).

60) R. Tamamushi, T. Takeuchi and N. Tanaka, 18th International Congress of Pure and Applied Chemistry, Montreal, Canada (1961), No. B3-39.

61) H. Shirai, Nippon Kagaku Zasshi 81, 1248 (1960).

62) T. Takahashi and H. Shirai, Rev. Polarog. (Kyoto) 11, 155 (1963).

63) N. Tanaka, Y. Kikuchi and Y. Sato, Talanta 11, 221 (1964).

64) K. Mor inaga, Rev. Polarog. (Kyoto) 9, 97 (1961).

65) K. Eda, Nippon Kagaku Zasshi 80, 343, 347, 349, 361, 365, 708 (1959); 81, 689. 875, 879 (1960).

66) S. Ueda, A. Watanabe and F. Tsuji Denki-Kagaku 30, 58\%, 657 (1962); 31, 32 (1963).

67) S. Ueda, F. Tsuji and A. Watanabe, ibid. 29, 634 (1961).

68) A. Watanabe, F. Tsuji and S. Ueda, ibid. 29, 701 (1961).

69) S. Ueda, A. Watanabe and F. Tsuji, ibid. 30, 576 (1962).

70) K. Tsuji, Sci. Pap. Inst. Phys. Chem. Res. (Tokyo) 56, 116 (1962); Rev. Polarog. (Kyoto) 11, 233 (1963).

71) N. Tanaka, R. Tamamushi and A. Takahashi, Collection Czech. Chem. Commun. 25, 3016 (1960).

72) N. Tanaka, Y. Kikuchi and Y. Sato, Bull. Chem. Soc. Japan 36, 759 (1963).

73) T. Fujinaga and M. Maruyama (ed.), Kagaku-no-Ryoiki, Suppl. issue, Polarography, Vol. 1, (1962). Nankodo, Tokyo.
74) M. Ishibashi, T. Fujinaga and A. Saito, Bunseki Kagaku 8, 321 (1959).

75) M. Senda, I. Tachi, Denki-Kagaku 27, 83 (1959).

76) T. Kambara and T. Ishii, Rev. Polarog. (Kyoto) 9, 30 (1961).

77) A. Saito, Nippon Kagaku Zasshi 82, 214 (1961).

78) E. Niki, "Advances in Polarography", ed. I. S. Longmuir, Vol. 3, p. 991.(1960), Pergamon, London

79) A. Saito, Nippon Kagaku Zasshi 82, 214, 715, 718 (1961).

80) H. Shirai, ibid. 80, 609, 1435 (1959); 81, 1248, 1578 (1960); 82, 339 (1961).

81) Y. Asahi, Yakugaku Zasshi 79, 1548, 1559, 1563, 1565 (1959); 80, 679, 684, 1093, 1097, 1226 (1960).

82) M. Senda and I. Tachi, Rev. Polarog. (Kyoto) 10, 79 (1962).

83) T. Kambara, A. Hayashi and Y. Yoshimi, ibid. 10, 131 (1962).

84) T. Fujinaga and M. Maruyama (ed.), Kagaku-no-Ryoiki, Suppl. issue, Polarography, Vol. 2, (1963) Nankodo, Tokyo.

85) M. Shinagawa, H. Imai and H. Nezu, Bull. Chem. Soc. Japan 34, 445 (1961).

86) S. Misumi and Y. Ide, Memoirs Fac. Sci. Kyushu Univ., Ser. C. Chem. 3, No. 3, 205 (1961).

87) N. Maki, Ann. Rept. Radiation Center, Osaka Pref. 3, 26 (1962).

88) Y. Saito and K. Okamoto, Rev. Polarog. (Kyoto) 10, 227 (1962).

89) K. Okamoto, ibid. 11, 225 (1963); 12, 40, 50 (1964).

90) K. Okamoto, Bull. Chem. Soc. Japan 36, 1381 (1963); 37, 293 (1964).

91) K. Okamoto, Kagaku-no-Ryoiki, Suppl. issue, Polarography, ed. by T. Fujinaga and M. Maruyama, Vol. 2, p. 25. (1963), Nankodo, Tokyo.

92) M. Senda and T. Nagai, ibid., p. 167.

93) Y. Takemori, T. Kambara and I. Tachi, 
Z. phys. Chem., Sonderheft 89 (1958).

94) M. Ishibashi, T. Fujinaga, T. Nagai and S. Kakumoto, Nippon Kagaku Zasshi 81, 88, 744 (1960).

95) T. Nagai. ibid. 81, 93, 250, 252, 254, 256 (1960).

96) M. Ishibashi, T. Fujinaga, A. Saito and K. Izutsu, ibid. 80, 478 (1959).

97) Y. Takemori, Rev. Polarog. (Kyoto) 9, 246 (1961).

98) T. Fujinaga and C. Takagi, Nippon Kagaku Zasshi 84, 972 (1963).

99) Y. Takemori, T. Kambara, M. Senda and I. Tachi, J. Phys. Chem. 61, 968 (1957).

100) T. Murayama, Sci. Repts. Tohoku Univ., First Ser. 45, 84 (1961).

101) N. Tanaka, K. Ebata, T. Takahari and T. Kumagai, Bull. Chem. Soc. Japan 35, 1836 (1962).

102) Y. Takemori, Rev. Polarog. (Kyoto) 12, 63 (1964).

103) S. Oka and H. Matsuda, Kagaku-noRyoiki, Suppl. issue, Polarography, ed. by T. Fujinaga and M. Maruyama, Vol. 2, p. 81. (1963), Nankodo, Tokyo.

104) M. Shinagawa, H. Nezu; A. Muromatsu and S. Oka, Rev. Polarog. (Kyoto) 11, 183 (1963).

105) Y. Okinaka, S. Toshima and H. Okaniwa, Denki-Kagaku 31, 854 (1963); Talanta 11, 203 (1964).

106) S. Oka, Nippon Kagaku Zasshi 81, 1202, 1206, 1356 (1961).

107) M. Ishibashi and T. Fujinaga, DenkiKagaku 24, 375, 525 (1956); Anal. Chim. Acta 18, 112 (1958).

108) T. Fujinaga, Kagaku-no-Ryoiki, Suppl. issue, Polarography, ed. by T. Fujinaga and M. Maruyama, Vol. 2, p. 119. (1963), Nankodo, Tokyo.

109) Ref. 33), and other related papers.

110) N. Tanaka, R. Tamamushi and M. Kodama, Bull. Chem. Soc. Japan 33, 14 (1960).
111) R. Tamamushi, Denki-Kagaku 27, 60 (1960).

112) T. Hashino, Rev. Polarog. (Kyoto) 10, 23 (1962).

113) R. Tamamushi and N. Tanaka, Z. Phys. Chem. N. F. 21, 89 (1959).

114) R. Tamamushi and N. Tanaka, ibid. 28, 158 (1961).

115) H. Imai, S. Inouye and S. Chaki, Bull. Chem. Soc. Japan 31, 767 (1958).

116) H. Imai, S. Inouye and S. Chaki, ibid. 32, 994 (1959).

117) H. Imai, S. Chaki and S. Inouye, ibid. 33, 269 (1960).

118) N. Tanaka and M. Kodama, Nippon Kagaku Zasshi 79, 409 (1958).

119) N. Tanaka, R. Tamamushi and M. Kodama, Anal. Chim. 'Acta 20, 573 (1959).

120) R. Tamamushi, S. Momiyama and N. Tanaka, ibid. 23, 585 (1960).

121) M. Kodama, Bull. Chem. Soc. Japan 34, 714 (1961).

122) M. Kodama, H. Ouchi and S. Wakui, Nippon Kagaku Zasshi 84, 241 (1963).

123) Y. Mashiko, N. Hosoya and K. Ito, Rev. Polarog. (Kyoto) 10, 33 (1962).

124) Y. Okinaka, Kagaku-no-Ryoiki, Suppl. issue, Polarography, ed. by T. Fujinaga and M. Maruyama Vol. 2, p. 149. (1963), Nankodo, Tokyo.

125) R. Tamamushi, ibid., p. 139.

126) T. Ozaki and T. Nakayama, Nippon Kagaku Zasshi 81, 98 (1960).

127) T. Ozaki and T. Nakayama, ibid. 82, 46 (1961).

128) T. Ozaki, Bull. Educ. Fac. Shizuoka Univ. 11, 133 (1960).

129) J. Suzuki and T. Ozaki, Bull. Chem. Soc. Japan 37, 230 (1964).

130) H. Goto, S. Suzuki and T. Saito, Nippon Kagaku Zasshi 84, 41 (1963).

131) A. Kozawa, Denki-Kagaku. 30, 720 (1962); 31, 183, 315, 618, 682 (1963).

132) S. Shibata, Bull. Chem. Soc. Japan 33, 
1633 (1960); 36, 53, 525 (1963); 37, 410 (1964).

133) R. Takahashi, Rev. Polarog. (Kyoto) 8, 17 (1960).

134) S. Ikeda, ibid. 10, 51 (1962).

135) S. Musha, T. Wasa and K. Tani, ibid. 11, 169 (1963).

136) R. Takahashi, ibid. 9, 116 (1961); 11, 190 (1963).

137) M. Shinagawa and T. Yanagi, ibid. 7, 144 (1959).

138) T. Hashino and M. Ichise, Denki-Kagaku 30, No. 13 (Suppl. issue), 23 (1962).

139) T. Fujinaga and T. Hashino, ibid. 31, 485 (1963).

140) S. Yoshizawa, Rev. Polarog. (Kyoto) 9, 2 (1961).

141) T. Nishi and M. Ichise, Denki-Kagaku 32, 155 (1964).

142) H. Kido and H. Hayakawa, ibid. 27, 24 (1959).

143) H. Kido, M. Ishibashi and Y. Hayakawa, ibid. 28, 117 (1960).

144) Y. Hayakawa and Y. Imakita, ibid. 28, 592 (1960).

145) Y. Hayakawa, Yoyuen 3, 817 (1960).

146) Y. Kimura and Y. Hayakawa, DenkiKagaku, 32, 160 (1964).

147) H. Goto, S. Suzuki and T. Saito, Nippon Kagaku Zasshi 83, 883 (1962);84, 332 (1963).

148) M. Shinagawa and T. Yanagi, Bunseki Kagaku 10, 1026 (1961).

149) M. Shinagawa, N. Okamoto and C. Nakano, Rev. Polarog. (Kyoto) 5, 115 (1957).

150) M. Shinagawa, Kagaku-no-Ryoiki, Suppl. issue, Polarography, ed. by T. Fujinaga and M. Maruyama, Vol. 2, p. 103. (1963), Nankodo, Tokyo.

151) M. Nakagawa, Rev. Polarog. (Kyoto) 9, 194 (1961).

152) T. Fujinaga, H. A. Brodowsky, T. Nagai and K. Yamashita, ibid. 11, 217
(1963).

153) M. Shinagawa, H. Nezu and T. Yamada, ibid. 10, 163 (1962).

154) M. Shinagawa and H. Nezu, ibid. 7, 165 (1959).

155) H. Okashita, ibid. 7, 176 (1959).

156) T. Fujinaga and K. Izutsu, ibid. 9, 36 (1961).

157) T. Fujinaga and K. Izutsu, Bunseki Kagaku 10, 63 (1961).

158) N. Tanaka and H. Ogino, J. Electroanal. Chem. 7, 332 (1964).

159) N. Tanaka and K. Kato, Bull. Chem. Soc. Japan 32, 516 (1959); 33, 417 (1960).

160) N. Tanaka, M. Kamada, H. Osawa and G. Satô, ibid. 33, 1412 (1960).

161) N. Tanaka and H. Ogino, ibid. 34, 1040 (1961).

162) N. Tanaka, Y. Saito and H. Ogino, ibid. 36, 794 (1963).

163) M. Kodama and N. Abe, Nippon Kagaku Zasshi 83, 679 (1962).

164) M. Kodama and M. Hashimoto, Bull. Chem. Soc. Japan 35, 1802 (1962).

165) M. Kodama and S. Naito and M. Ebina, Nippon Kagaku Zasshi 84, 576 (1963).

166) N. Tanaka, K. Kato and R. Tamamushi, Bull. Chem. Soc. Japan 31, 283 (1958).

167) N. Tanaka and Y. Sakuma, ibid. 32, 578 (1959).

168) N. Tanaka and K. Kato, ibid. 32, 1376 (1959); 33, 1236 (1960).

169) K. Kato, ibid. 33, 600 (1960).

170) N. Tanaka and M. Kamada, ibid. 35, 1596 (1962).

171) N. Tanaka, H. Osawa and M. Kamada, ibid. 36, 67, 530 (1963).

172) N. Tanaka and H. Ogino, ibid. 36, 175 (1963).

173) S. Koide and I. Tachi, Denki-Kagaku 23, 522 (1955).

174) T. Fueno, K. Asada, K. Morokuma and J. Furukawa, Bull. Chem. Soc. Japan 32, 1003 (1959). 
175) K. Fukui, K. Morokuma, H. Kato and T. Yonezawa, ibid. 36, 217 (1963).

176) Y. Asahi, Rev. Polarog. (Kyoto) 10, 135 (1962).

177) T. Kitagawa, ibid. 12, 11 (1964).
178) H. Uehara, Kagaku-no-Ryoiki, Suppl. issue, Polarography, ed. by T. Fujinaga and M. Maruyama, Vol. 1, p. 137. (1962), Nankodo, Tokyo.

179) K. Itsuki, ibid. p. 151. 